\title{
BILATERAL BREAST CANCER - CASE SERIES
}

\section{Surgery}

Dr. N.Murugesan Medical College And Post-graduate Institution Of Medical Science And Research (ESIC, PGIMS\&R), K.k.nagar, Chennai-78, Tamilnadu. College And Post-graduate Institution Of Medical Science And Research (ESIC, PGIMS\&R), K.k.nagar, Chennai-78, Tamilnadu. *Corresponding Author

Assistant Professor Department Of Surgery Employees State Insurance Corporation Medical College And Post-graduate Institution Of Medical Science And Research (ESIC, PGIMS\&R), K.k.nagar, Chennai-78, Tamilnadu. Dr. Bhanumati Medical College And Post-graduate Institution Of Medical Science And Research (ESIC, PGIMS\&R), K.k.nagar, Chennai-78, Tamilnadu.

Associate Professor Department Of Surgery Employees State Insurance Corporation Dr. Muthuraj Medical College And Post-graduate Institution Of Medical Science And Research (ESIC, PGIMS\&R), K.k.nagar, Chennai-78, Tamilnadu.

Associate Professor Department Of Surgery Employees State Insurance Corporation

Dr. Gajendran Medical College And Post-graduate Institution Of Medical Science And Research (ESIC, PGIMS\&R), K.k.nagar, Chennai-78, Tamilnadu.

\section{Prof. Dr.P.N. Shanmuga Sundaram}

Head of the Department Department Of Surgery Employees State Insurance Corporation Medical College And Post-graduate Institution Of Medical Science And Research (ESIC, PGIMS\&R), K.k.nagar, Chennai-78, Tamilnadu.

\section{ABSTRACT}

This is a presentation of four rare and interesting cases of bilateral breast cancer. The cases vary from Synchronous double primary carcinoma breast, bilateral infiltrating ductal carcinoma, bilateral synchronous metastatic carcinoma and metachronous breast carcinoma. The incidence of developing either primary or metastatic carcinoma in the other breast is increased in patients who already have carcinoma in one side and mammography contributes greatly to the detection of these lesions. (1) It is of significant prognostic value and important in deciding the clinical management based on the classification whether it is a primary or a secondary lesion.

\section{KEYWORDS}

Carcinoma Breast, Synchronous, Metachronous, Metastasis, Modified Radical Mastectomy, Chemotherapy.

\section{INTRODUCTION}

WHO in its Cancer country profile 2020 (India) has stated that Breast carcinoma is the most common cancer by incidence( $14 \%)$ and also by mortality(11.1\%)(2). Breast cancer may present as unilateral or bilateral.

Bilateral breast cancer can be broadly classified into two types, synchronous and metachronous cancers. Synchronous cancer is the condition in which the tumor develops in the contralateral breast within 6 months of origin of tumor in the index breast. If the tumor develops after 6 months then it is called as metachronous lesion. Both the types of synchronous cancers and metachronous cancers can be double primary or lesion of metastatic origin.

Synchronous bilateral breast carcinoma (SBBC) is an uncommon presentation(3) . Bilateral synchronous breast cancer accounts for 0.2$2 \%$ of all breast cancers (4)

Most of the tumors are metachronous (5). The bilateral lesion in the opposite breast can be either synchronous or metachronous.

Breast cancer is usually associated with local and lymphatic spread and with blood-borne spread to lungs, bones and liver. The treatment modalities changes with the type of lesion.

\section{CASE 1}

A 66 years old postmenopausal women presented with the complaints of lump in her left breast for the past 6 months and a lump in her right breast for the past 4 months of duration. There was no h/o nipple discharge, no h/o any ulcer over both the lumps. On examination, skin fixity was present on both the breast and lymph node was present in right breast. Metastatic work up was done, and abiding by chaudary millis et al criteria, patient was diagnosed as bilateral breast carcinoma $\mathrm{T} 4 \mathrm{bN} 1 \mathrm{MO}$ of right breast and T4bn0mo of left breast.

Since the lesion was synchronous double primary type, Patient underwent bilateral MRM and is on follow up.

(Pre Operative picture)

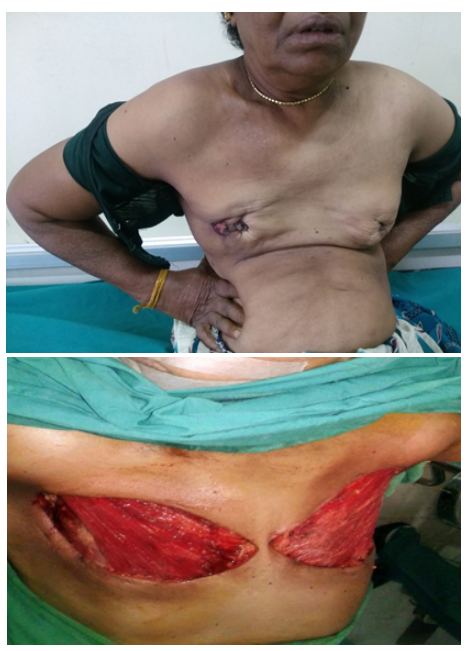

CASE 2:

A 55 years old postmenopausal women presented with complaints 
of Lump in the left breast for 1 year and with $\mathrm{H} / \mathrm{O}$ recent retraction of Right nipple. On examination whole of the left breast was occupied by lump and was contracted. Simultaneously a $4 \times 4 \mathrm{~cm}$ lump was present in right breast upper outer quadrant.

Trucut biopsies from both the lesion were taken and IHC done. The report was of infiltrating ductal carcinoma on both the sides. Oncologist was consulted regarding the procedure for treatment. Right sided MRM was done and since the lesion in the left breast was a locally well advanced cancer, neo adjuvant chemotherapy was given. She completed 4 cycles of chemotherapy and is on follow up.

\section{(Per Operative picture)}

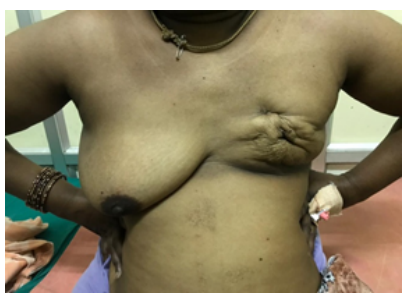

CASE 3:

A 62 years old postmenopausal women presented with the complaints of right breast lump for 1 year duration. The lump was not associated with pain and there was no ulceration. The patient had history of recent retraction of right nipple and there was a history of lump in her left breast for the past 6 months duration. On examination a $5 \times 6 \mathrm{~cm}$ lump was present in her right breast in lower outer quadrant, with enlarged apical group of lymph nodes and right supraclavicular lymph node enlargement. Simultaneously a $4 \times 3 \mathrm{~cm}$ lump in her left breast was present in upper outer quadrant. On metastatic workup, a lesion was found in the $6^{\text {th }}$ segment and $7^{\text {th }}$ segment of liver. This was diagnosed as synchronous metastatic cancer and patient was started on palliative chemotherapy after consulting with oncologist.

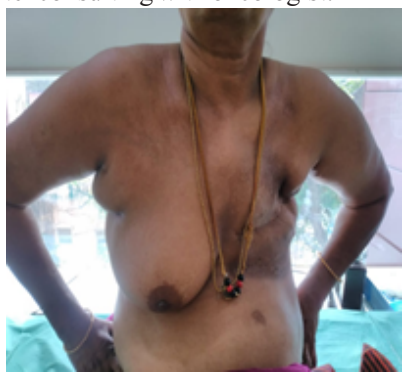

CASE 4:

A 68 Years old post-menopausal women was a known case of left breast carcinoma (diagnosed in 2017) and had underwent left sided MRM. The surgery was followed by 6 cycles of adjuvant chemotherapy. Now patient returned with complaints of lump in her right breast for 4 months duration.

On examination, left side scar was healthy and there was no mass palpable on the left side. Left axilla was normal.

On examination of right breast, there was a lump of size $5 \times 5 \mathrm{~cm}$ in upper outer quadrant and enlarged lymph node in central group. PET scan showed increased metabolic activity in right breast lesion and right axillary nodes. The diagnosis was that of metachronous breast cancer and she underwent right sided MRM.

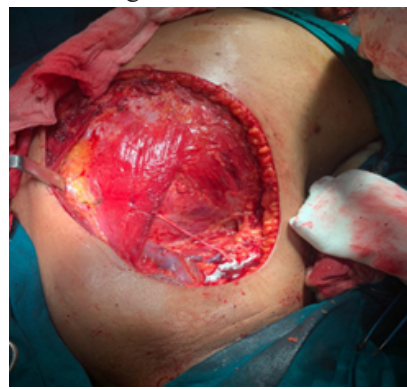

Synchronous and Metachronous cancers. Synchronous tumours can present as two or more tumours where each are malignant, but distinct from each other i.e. of different histological type and do not originate with metastasis from another tumor [6]. Synchronous cancer develops in a contralateral breast within 6 months of origin of tumor in an index breast. The incidence pattern of synchronous cancer is similar to that of unilateral disease, although without any notable trends in recent decades [7]. If the patient develops the same after 6 months then it is called as Metachronous lesion.]. Bilateral cancers are detected early by preclinical work-up, and classified as synchronous disease rather than diagnosed later as metachronous disease [8]. Nowadays, the incidence of local recurrences, bilateral cancer, and distant metastasis are reduced with the use of adjuvant systemic therapy, mainly tamoxifen and chemotherapy that became clinical practice [9]. Synchronous breast cancer has a poorer prognosis than metachronous or unilateral breast cancer (10].

\section{As per the Chaudary millis et al criteria:}

If the contralateral tumor is a primary tumor, it should meet the following:

- In-situ changes in the contralateral breast

- Histologically different

- Degree of differentiation is distinctly greater

- There should be no evidence of loco regional or distant metastasis in the absence of histological difference.

Both synchronous and metachronous tumors can be of double primary or metastatic lesion. In case of double primary synchronous, treatment modality is similar to unilateral breast cancer. In case of metastatic synchronous, treatment modality is similar to metastatic breast cancer. So, it is important to know whether the synchronous tumor is double primary or metastatic tumor. Based upon this, the treatment modalities change.

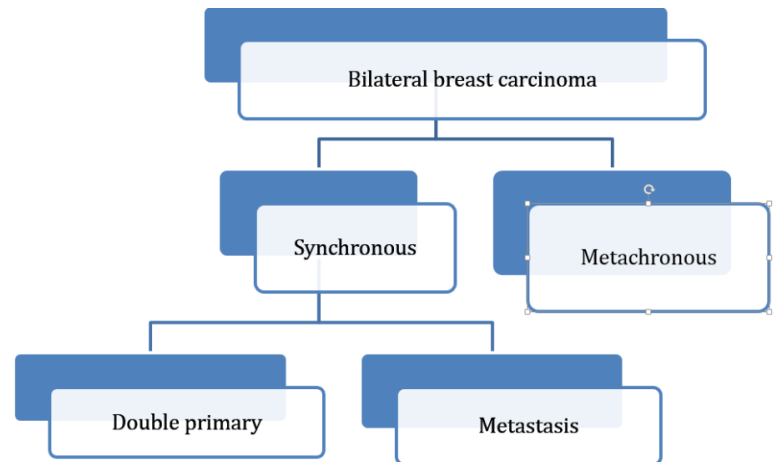

\section{CONCLUSION :}

- Bilateral breast cancer is a rare entity.

- Mammography of contralateral breast helps in picking up early lesion in the contralateral breast, so if a person presents with lump breast mammography is essential to look for any contralateral breast lesion.

- Based on chaudary millis et al criteria treatment modality changes.

- The prognosis also depend on the type of the second tumor Source of funds and conflict of interest is Nil.

\section{REFERENCES}

1. Egan 1976, Haagensen 1971, Gutter 1976, Leis et al. 1965

2. WHO cancer country profile 2020

3. Gollamudi SV, Gelman RS, Peiro G, Schneider LJ, Schnitt SJ, Recht A, Silver BJ, Harri JR, Connolly JL. Breast conserving therapy for stage I-II synchronous bilateral breas carcinoma. Cancer. 1997; 79:1362-1369.

4. Chaudery MA, Mills RR, Hoskins EOL, Halder M, Bulbrook RD, Cuzick J, Hayward JL. Bilateral breast cancer: a prospective study of disease incidence. Br J Surg. 1984 71:711-714

5. Donovan AJ. Bilateral breast cancer. Surg Clin North Am. 1990; 70:1141-1149.

6. Warren S, Gates O. Multiple primary malignant tumours. A survey of the literature and statistical study. AM J Cancer. 1932; 16:1358-1405.

7. Hartman M, Czene K, Reilly M, Adolfsson J, Bergh J, Adami HO, Dickman PW, Hall P. Incidence and Prognosis of Synchronous and Metachronous Bilateral Breast

8. McPherson K, Steel CM, Dixon JM. ABC of breast diseases: Breast cance epidemiology, risk factors, and genetics. BMJ. 2000; 321:624-628.

9. Fisher B, Dignam J, Bryant J, DeCillis A, Wickerham DL, Wolmark N, Costantino J, Redmond C, Fisher

10. Bailey MJ, Royce C, Sloane JP, Ford HT, Powles TJ, Gazet JC. Bilateral carcinoma of the breast. Br J Surg. 1980; 67:414-16.

DISCUSSION:

Bilateral breast cancer can be broadly classified into two types, 